\title{
A Philosophy of Book Selection for Smaller Academic Libraries
}

\author{
By STUART A. STIFFLER
}

The Purpose of this paper shall be to outline some of the controlling criteria which should underlie a sound acquisitions policy for the smaller academic libraries. It disclaims any intention of presenting rules of thumb constituting an absolute system for the selection of materials. The effective development of academic library book collections, however, is dependent upon the understanding and acceptance of certain larger assumptions which fall neither within the category of administrative techniques nor within these critical standards of judgment applicable to the content of the several subject disciplines. They spring rather from the general organization and the social development of knowledge itself.

It is hardly necessary to point out that, from a statistical point of view, the major problem in acquisitions policy for smaller institutions with limited financial resources is that of selection from a constantly increasing rate of publication. In the field of history, for example, a library with a book budget of $\$ 13,000$ to $\$ 15,000$ per year may find that it can purchase only one volume in ten of current annual publication in this field. When the necessity for acquiring some older materials, together with books published in English in Great Britain and in other foreign countries, is considered the problem is, of course, greatly intensified.

It has been said that libraries are not made, they just grow. Any librarian who has worked with a collection of books over an extended period will be aware of the large element of truth in this. The
Mr. Stiffler is Associate Librarian of Hiram College.

growth of academic book collections has, of course, always been subject to some measure of rational control. But the typically uneven and disorderly character of this growth raises again the question of the proper relationship between the planned and the necessarily fortuitous elements in the development of the book collection. What should the librarian's responsibility be in supervising the quantitative and qualitative growth of his book collection?

Some librarians appear to follow, as much as possible, a simple "stimulus-response" buying policy. Especially is this so if general funds are limited and if the budget is departmentally allocated. This policy, insofar as it is a decision (or an implicit acquiescence) of the librarian, represents too often a failure to discharge the full measure of one's professional responsibility. On the other hand in a small institution it is typically the responsibility of one or two librarians to survey the entire scope of publication which may be divided among as many as a dozen or more specialists in larger institutions. Obviously such a situation requires a careful estimate of staff capability, a deliberately planned division of labor and, of necessity, a heavy reliance upon faculty for the initiation of orders. However, to assign this role entirely (or almost completely) to faculty in most instances suggests a faulty estimate of relative responsibility or, possibly, just a failure of nerve on the part of the librarian. 
What theoretical guidelines should the librarian adopt, then, if he is to assume an active role in book selection? Every institution presents its unique problems. The points included in any sound book selection policy statement are basic. What are the educational aims of one's institution? What is the general trend in departmental and in total enrollments? What are the specific trends in research and teaching interest within each department? What is the pattern of curriculum development? What is the proximity of one's institution to other book collections? The introduction of Honors programs and the generally increased emphasis upon independent study is, for example, a development which can significantly alter one's total purchasing program.

As a background for selection these policy considerations should be tied in with a carefully written estimate of the strengths and weaknesses of one's collection. The more detailed and specific this can be made, the better; but in any case, it will have to be constantly amended and expanded with changes in curriculum and faculty and with the continuing evaluation of the collection. But, beyond this, what general applicability can theoretical considerations have for the numerous individual book collections, each with its own requirements?

In the first place, a book is always, ideally, evaluated originally, or in review, by the librarian on its own merits. He utilizes his own knowledge, consults staff or faculty members and checks standard bibliographies, check lists and reviews. The librarian remains ultimately responsible for the qualitative character of his book collection. He may on occasion think it necessary to express a negative opinion of a book or to summarize reviewers' professional consensus to the individual who requests such a book. And he must retain the ultimate authority to reject a book under consideration.
But with exceptions to be noted, a volume should not usually be selected exclusively on the basis of its individual merit. The questions must be asked, what is the relevance of the book to our requirements in terms of the educational aims of our institution?, in terms of student and faculty interests?, of the level of demand and enrollment in the various courses?, of the relative strengths in the collection as defined in one's written evaluation of the collection?, of the degree of specialization and level (or type) of treatment of the volume in relation to the clientele served? Decision for purchase of most volumes must be based upon careful assessment of the multiple selection criteria involved.

To select a book without reference to these extrinsic critera will, in the long run, materially decrease the general utility of the collection to the library's public. As a general underlying principle it is important to view the library collection not as composed of isolated bookunits, deriving their organic character only from physical proximity and the residual subject analysis provided by the classification system, the card catalog, indexes, and printed bibliographies. In a substantive sense a book collection is not composed of books as physical objects in space, but rather it consists of ideas or themes, events, interpretations having some structural coherence in terms of collective treatment in the total body of material selected and analyzed. By "structural coherence" is meant that the ideational content of a given volume is viewed, insofar as possible, in its manifold relations to the corresponding or related content of all other physical units in the collection. This criterion should be qualified, as shall be explained below, by the admission of books relatively comprehensive and self-contained and which further appear as significant idea-complexes around which to build.

The well selected book collection, 
then, poses a complex problem in applied social epistemology. Accordingly, the librarian must be sensitive to the evolving organization of knowledge, and to the interrelationship of the ideas, the events, and the broader themes which he is evaluating. This "sensitivity" involves not only some sense of the logical organization of knowledge (considered as idea, event, or theme) but of the associative or analogical element which, since it is involved in research and imaginative thinking, is ultimately a factor in the analysis and selection of books.

Now it follows as a corollary of the fact that the collection as a whole possesses its own distinctive structural characteristics that the individual book is not, typically, a self-contained unit of knowledge. Anyone who has worked with books knows that the book is not often a comprehensive, logically and coherently organized vehicle of expression, precisely fitted to a researcher's need, even when the subject in view is but one clearly delimited aspect of a broader topic. Further, most library users naturally select a research topic without reference to the topic's compactness or unity of treatment in the materials which constitute the library collection.

From the researcher's point of view the scattering of information on a research topic is the result of the natural divergence among patterns of definition of subject, of logical organization, of level and mode of treatment, and of canons of pertinency as conceived by himself and by the authors of that body of material of potential use to him. This divergence is complicated by the cumulative growth (and sometimes the obsolescence) of knowledge which may, in itself, alter with time the effective ideational relationship of a given volume to related volumes in the collection. This scattering effect is ultimately a result of subjective differences in modes of thinking together with the social growth of knowledge and the changing pattern of its physical organization. The librarian can only hope to reduce somewhat the dissimiliarity in the mental pictures of authors and library users by judging books against some operational conception of his clientele's subjective type of mind. The difficulty in applying this approach with any great precision should not, however, be a matter of great concern. The complete elimination of "cross purpose" between author and library user is not the ultimate goal. Since a basic element of research is the imaginative reorganization of recorded thought, absolute subjective correspondence would eliminate the possibility of research itself.

If the book is to be of maximum value it must, then, be judged on the basis of its ideational content viewed within the context of the internal structure of the collection and the external requirements of the clientele. Otherwise it is conceivable that one may build a collection of excellent books with but very few topics or themes reliably treated in depth. Brooks Adams' observation of fifty years ago that "men of liberal education have collected libraries who have never been taught to generalize. . . When a book is supposed to have a certain degree of merit it is deemed worthy of purchase, almost regardless of subject" ${ }^{1}$ is probably still true of the practice of many librarians today. In sum the physical units which collectively constitute the treatment of even a delimited topic are typically numerous and often physically scattered in terms of the formal classification structure. Even when expertly performed, the organization of subject analysis cannot be expected to remedy the deficiencies of book selection without close attention to the structural characteristics of knowledge. For this reason I think that even in small collections with limited budgets the indispensable standard of the "well-balanced" collec-

\footnotetext{
${ }^{1}$ The New Empire (New York, Macmillan, 1902), p. xxvi.
} 
tion should not be made a fetish. The list of authors or broad topics almost automatically selected should not be too extensive or too rigidly adhered to. Some imbalance in coverage may have to be tolerated in planning for selected coverage of a few specialized ideas, themes, or events.

Several categories may be enumerated which should help organize in the librarian's mind the evaluation and selection of books. Before considering these general categories, it should be acknowledged, that, in order to reduce the scattering effect discussed above, some books will immediately eliminate themselves by virtue of the public to which they are addressed, or, more specifically, because of their degree of specialization, or the level and type of treatment they exhibit. Although some may be selected if specifically requested or if judged to be of standard or seminal importance, most will be quickly eliminated. The degree of a book's specialization in relation to the size of one's collection or, more properly, the size of the collection in the specialized subfield which the volume treats is an initial consideration.

The categories may be enumerated as follows:

1. First, there are books whose selection is, in most academic libraries, quite properly determined by the formal structure of the selection process. The faculty selects these books subject to the informal advice and review of the librarian. These volumes may, of course, be valuable from the point of view of the criteria outlined below. But such coincidence must be considered to be considerably fortuitous.

2. The second category consists in the works of "standard" authors which are selected almost automatically. To permit flexibility the list should be informal and not too extensive. Generally speaking, the less significance critical opinion attaches to an author, the more the author's subject and style should be imme- diately considered in relation to the interests and tastes of the libraries publics and, ultimately, the more attention should be focused upon the intrinsic merits of the book itself.

3. The third category includes books selected on specialized subjects, themes, ideas, or events (qualified by mode of treatment). Books on certain subjectsdepending upon local interest and demand-may receive priority consideration for purchase. This category may, however, sometimes be chosen without reference to immediate demand in order to add depth to selected ideas, themes, and events on which some demand may reasonably be anticipated. Automatic buying on topics should, however, be carefully controlled by the pattern of changing needs and by the merits of the book itself. Where demand is very heavy or published material is scarce, critical standards may on occasion be lowered somewhat.

4. The fourth category is made up of miscellaneous material, added for symmetry or for "rounding out the collection" and overlaps to some degree with category two, "standard" authors. Priority consideration within this category should be given to books for which anticipated demand may be determined with some assurance. Although these judgments are difficult at best, by noting the pattern of student and faculty interests and by analyzing curricular trends one may choose well within this category. Types of material which may be subsumed under this category include standard or classic works for which there is continuing demand. Also included are books in fields which have been developed in the past but which have receded in relative importance because of changing personnel or changing interests and because of curricular changes. This latter material should be "kept up" by the librarian to the extent that the budget allows, as the area in question may well again emerge within the pur- 
view of faculty or student interest. Or these books may attract research interest from allied fields or may be used for papers in freshman English courses.

5 . The fifth category is normally small in relative financial priority but nonetheless vital in qualitative importance. It encompasses new books which do not fall within the first four enumerated categories. These materials should challenge the full range of the librarian's insight, reinforced by a certain measure of educated guessing. This category may be designated as including those works which, although apparently not of immediate interest to students and faculty, appear destined to become standard or definitive surveys of a subject field, of a theme, an idea, an event. These are not selected purely intuitively, however, but in part upon the intrinsic merits of the volume in relation to a logical projection of needs and interests of the library's public estimated from all available evidence.

These points then may be summarized as follows. The librarian always should bear an active responsibility in the development of the book collection. This responsibility should rest upon an evaluation of the differential strengths of his collection in relation to the interests of his clientele and to the educational aims and curricular trends of his institution. To implement effectively this responsibility, there should be established as basic assumption in the librarian's mind a clear conception of his book collection as an organic body of knowledge with its own peculiar structural organization.

The competent selection of a new book title, especially in institutions with very limited resources, frequently involves the consideration of multiple determining criteria. Each new title, consequently, might be considered in terms of the categories of valuation here outlined. The specific nature of the decisions which may be deduced from these determining guidelines must be dictated by the local situation. A survey program of current reviewing and indexing publications should be established to provide a consistent and rational implementation of these guidelines to the book selection program. It is the frequent complexity and the considerable element of subjectivity involved which should make the selection process a constantly interesting and challenging professional undertaking.

\section{Audio-Visual Workshop}

The ALA Audio-Visual Committee in cooperation with the LAD Personnel Administration Section's In-service Training Committee is sponsoring a preconference workshop at the Pick-Congress Hotel in Chicago July 12-14. The workshop is especially designed for librarians working with AV materials in school, college, university and public libraries. It is directed toward staff members who may have either part-time or full-time responsibility for such materials. The registration will be limited to 200 .

The opening session on Friday evening, July 12, will feature a talk on Educational Value of AV Materials in Library Services, including the implications of the newer media by Seth Spaulding, Educational Media Branch, USOE. Other sessions will cover such topics as sources of materials, film evaluation and criticism, and the utilization of audio-visual materials. A session devoted to problem clinics also will be included. A final luncheon meeting on Sunday, July 14 will have as featured speaker Robert Hudson of the National Educational Television and Radio Center who will talk on "New and Future Trends in the Use of Audio-Visual Materials." 